precipitant factor, namely major surgery or infection. Agressive treatment must be startted as soon as possible.

\section{FRI0183 ANTICARDIOLIPIN ANTIBODIES IN WOMEN WITH UNEXPLAINED PREGNANCY LOSS}

${ }^{1}$ RR Petrovic, ${ }^{2} \mathrm{Z}$ Mikovic, ${ }^{1} \mathrm{M}$ Petrovic, ${ }^{1} \mathrm{U}$ Srejic, ${ }^{1} \mathrm{M}$ Roganovic. ${ }^{1}$ Clinical Department, Institute of Rheumatology-Belgrade; ${ }^{2}$ Risk Pregnancy Department, Narodni Front Gynecologycal and Obstetrics University Hospital, Belgrade, Yugoslavia

\subsection{6/annrheumdis-2001.252}

Background Recurrent pregnancy loss is one of the major clinical features of antiphospholipid syndrome (APS). Although pregnancy losses in patients with antiphospholipid antibodies typically occur after the 10th week of gestation, early losses and premature birth also take place. Preliminary classification criteria for APS precisely define pregnancy morbidity associated with anticardiolipin antibodies (aCL) and/or with lupus anticoagulant (LA) as follows: 1) one or more unexplained fetal deaths; 2) one or more premature births; 3 ) three or more unexplained consecutive spontaneous abortions before the 10th week of gestation, when other causes (endocrine, genetic, and morphological) have been excluded. ${ }^{1}$

Objectives To assess the prevalence of elevated levels of anticardiolipin antibodies in otherwise healthy women with history of unexplained pregnancy losses and to investigate prevalence of APS among them.

Methods 29,8 \pm 5,3

A cross-sectional study comprised fifty women (mean age $29,8 \pm 5,3$ years) with a history of unexplained pregnancy losses (median 3; range 1-6). None of these women had anatomical, endocrine, genetic or infective cause for miscarriage. Anticardiolipin antibodies of IgG and IgM isotype were measured by a standardised ELISA for beta2-GPI- dependent aCL.

Results 14 out of 50 (28\%) women had elevated levels of aCL IgG (5) or IgM (6) or both (3) isotypes. Comparing aCL positive and aCL negative women, we found statistically significant difference in women age $(32,3 \pm 5,85$ vs. $28,8 \pm 4,8$ years; $p<$ 0,02 ) and fetal age at the time of miscarriage (median 18 vs. 10 weeks; $\mathrm{p}<0,0001)$. Ten out of these 14 women fulfilled criteria for APS. During the follow-up of these patients that has lasted several years (3-5), 2 patients have developed full-blown of primary APS that includes thromboembolic events, and the other 3 were diagnosed as systemic lupus erythematosus (2) and overlap syndrome (1) with secondary APS.

Conclusion Elevated levels of anticardiolipin antibodies in women with unexplained pregnancy losses imply the presence of antiphospholipid syndrome. In fifty percent of these patients, full development of primary APS or secondary APS associated with systemic lupus erythematosus can be expected.

\section{REFERENCE}

1 Wilson WA, Gharavi $A E$, Koike $T$, et al. International consensus statement on preliminary classification criteria for antiphospholipid syndrome: report of an international workshop. Artritis Rheum. 1999;42:1309-11

\section{Scleroderma and related syndromes}

\section{AB0105 DYNAMICS OF HUMORAL IMMUNITY INDICES IN SYSTEMIC SCLEROSIS PATIENTS DEPENDING ON THE THERAPY CARRIED OUT}

AB Zborovsky, IP Gontar, AV Alexandrov, LA Maslakova, GF Sychova, OI Emelyanova. Laboratory for Clinical Immunology, Research Institute for Clinical and Experimental Rheumatology, Volgograd, Russia

\subsection{6/annrheumdis-2001.253}

\section{Background}

Objectives The aim of our study was to improve immunological control of specific antibodies (Ab) dynamics in blood of systemic sclerosis (SSc) patients during the therapy carried out using immunofluorescent (IFA) and immunoenzyme (IEA) analyses taking advantages of immobilised magnosorbents (MS).

Methods The $\mathrm{Ab}$ towards denatured deoxyribonucleic acid (dDNA), ribonucleic acid (RNA), cardiolipin (CL) were determined by IEA method, Ab towards catalase (Cat) ? by IFA method in sera of 28 SSc patients using immobilised MS before and after hospital treatment. Immobilisation was carried out by method of emulsion polymerisation by Gontar et al. (1990) in nitrogen gas flow with magnetic material incorporation in polyacrilamid gel structure. All observed patients were divided into 3 subgroups: first group (32 patients) was treated with basic medicines (D-penicillamine, vasomotor medicaments, physiotherapy, exercises, massage, symptomatic therapy), second group (22 patients) -+ glucocorticosteroids; and third group (14 patients) -+ plasmapheresis (Pph).

Results There were not reliable decrease of studied $\mathrm{Ab}(\mathrm{p}>$ $0,05)$ in first group by IEA method, except Ab towards RNA (p $<0,05)$. However, we noted reliable decrease of $\mathrm{Ab}$ towards Cat $(\mathrm{p}<0,05$ after the course of therapy by IFA. In second group we revealed the decrease of $A b$ towards dDNA and RNA $(\mathrm{p}<0,05)$, while the dynamics of Ab towards Cat and CL were less evident $(p>0,05)$. The positive effect of Pph was noted in third group, where we revealed marked tendency to decrease of Ab towards dDNA $(\mathrm{p}<0,02)$, CL $(\mathrm{p}<0,001)$, Cat and RNA $(\mathrm{p}<0,05)$.

Conclusion The decrease of Ab towards dDNA, RNA, CL and Cat were noted in SSc patients during hospital treatment that allow the use of these indices as criteria for therapy efficiency and its duration. The use of extracorporal treatment method ? Pph in complex therapy of SSc patients allow to achieve clinical improvement in patients side by side with significant decrease $\mathrm{o}$ f Ab towards dDNA, RNA, CL and Cat.

\section{AB0106 THE MORPHOLOGICAL AND FUNCTIONAL CHANGES OF MICROCIRCULATORY VESSELS IN SYSTEMIC SCLEROSIS}

RT Alekperov, ES Match, NG Guseva. Microcirculation, Institute of Rheumatology of RAMS, Moscow, Russia

10.1136/annrheumdis-2001.254

\section{Background}

Objectives Systemic sclerosis (SSc) is characterised by the proof deterioration of microcirculation and the large structural changes of the microcirculatory vessels. The aim of the study was to investigate the relationship between functional and structural abnormalities of skin microcirculation in patients with systemic sclerosis (SSc). 
Methods Thirty patients with SSc aged 16 to 68 years (mean age $47,46+2,41$ yrs) were included in the study. Nineteen pts had limited cutaneous SSc (ISSc), and eleven - diffuse cutaneous SSc (dSSc). The morphological changes of skin capillaries were estimated by the nailfold capillary microscopy. The skin microcirculation was evaluated by laser Doppler flowmetry (LDF).

Results All studied patients showed an abnormal nailfold capillary pattern: enlargement of the capillary loop (dilated capillaries) and the loss of capillaries either diffusely or in limited areas. Depending on a degree of the nailfold capillaries changes the patients were divided into 3 groups: with mild (17 pts), moderate (14 pts) and severe (9 pts) changes. The level of basal skin blood flow in first group of the patients was $0,624+$ $0,031 \mathrm{v}$. In second group of the patients basal skin blood flow was $0,361+0,050 \mathrm{v}$ and there was also significantly below, when compared with first group of patients $(p=0,002)$. The lowest level of basal skin blood flow $0,212+0,063 \mathrm{v}$ was observed in the patients of third groups and also was significantly smaller than in the patients of first group $(p<0,001)$. There wasn't a statistically significant difference in basal skin blood flow levels between 2nd and 3rd groups of the patients. The level of basal skin blood flow closely correlated with number of capillaries $(r=0,73 ; p<0,001)$. In the patients with $\mathrm{dSS} c$ the greater decrease of number of capillaries was observed, than in the patients with ISSc. Basal skin blood flow in dSSc was considerably below, than in 1 SSc $(0,438+0,040 \mathrm{v}$ and $0,250+$ $0,063 \mathrm{v}$ respectively; $\mathrm{p}=0,02$ ).

Conclusion Thus, the microcirculation abnormalities closely correlated with structural changes of capillaries in SSc.

\section{AB0107 MULTIPLE FIBROSIS: TWO CASES OF SUCCESSFUL TREATMENT}

NG Guseva, MN Starovoitova, TA Nevskaya. Department of Systemic Sclerosis, Institute of Rheumatology of RAMS, Moscow, Russia

10.1136/annrheumdis-2001.255

\section{Background}

Objectives Multiple fibrosis (MF) is a slowly progressive disease of unknown cause characterised by localised connective tissue accumulation with the formation of multiple dense sclerotic foci leading to the internal organ dysfunction. It?s a rare and often fatal disease resulting in the visceral organ insufficiency. The most common localizations of the fibrotic lesions are retroperitoneal, mediastinal and lung fibrosis, pseudotumor of pancreas, sclerosing cholangitis. A disease process is usually difficult to stem and often impossible to reverse. There is no specific treatment for MF.

Methods

Results We report two cases of successful MF treatment with the combination of D-penicillamine (DPA) and steroids (S). A. $36 \mathrm{yr}$ old male presented with $4 \mathrm{yr}$ history of ?cancer like? symptoms: progressive fatigue, weight loss, subfebrile fiver, accelerating ESR $(40 \mathrm{~mm} / \mathrm{h})$, pulmonary (dry cough, dyspnoea, atelectasis of the left lower lobe of the lung by $\mathrm{X}$ ray and dense ?tumour? 60 $\mathrm{mm}$. in diameter in the core part of the left lung with a massive ?infiltration? spreading along the lower pulmonary vein by thoracotomy) and eye (loss of sight and right eye pain, unilateral scleral congestion) manifestations. With suspicion on the lung and eye cancers the total left pulmonectomy and right eye enucleation were carried out without any state improvement. Two yr later fasciitis, hepatosplenomegaly and new round foci in the right lung $(15 \mathrm{~mm})$ and pancreas $(27 \times 35 \mathrm{~mm})$ were found. MF was confirmed by histopathological finding and the combined therapy with DPA $1000 \mathrm{mg} / \mathrm{d}$ and oral steroids $30 \mathrm{mg} / \mathrm{d}$ (decreasing to $15 \mathrm{mg}$ daily after 0.5 year and remaining the same for 1.5 year) was prescribed. Over the subsequent 4 months the general condition of the patient improved, the temperature subsided, fasciitis and abdomenalgia disappeared completely, the pt gained $7 \mathrm{~kg}$ of weight, ESR diminished to normal levels. In a year we revealed obvious decreasing of the liver and spleen sizes and complete disappearance of the foci in the right lung and pancreas. During a 9 yr follow up we did not find any fibrotic foci in tissues, all laboratory tests are within normal limits. The pt receives daily maintenance dose of $125 \mathrm{mg}$ DPA and $7.5 \mathrm{mg}$ S. No side effects of the drugs have been noticed.

The second patient, a 39 yr old female with Ormond?s disease (retroperitoneal fibrosis which led to squeeze the ureters and bilateral hydronephrosis) had also been operated on - left nephrectomy - before a correct diagnosis was made. The administration of DPA $500 \mathrm{mg} / \mathrm{d}$ and S $20 \mathrm{mg} / \mathrm{d}$ check the progression of the disease during two years.

Conclusion Our results support data on successful use of the combined therapy with DPA and S in MF. Such drug treatment allowes to get a reverse development of the fibrotic lesions and to maintain a long stable remission of the disease.

\section{AB0108 COMPLICATIONS AND FORMAL PATHOGENESIS OF PROGRESSIVE SYSTEMIC SCLEROSIS. A RETROSPECTIVE STUDY}

${ }^{1} \mathrm{M}$ Bély, ${ }^{1} \mathrm{~T}$ Szentjóbi Szabó, ${ }^{1} \mathrm{P}$ Kapp, ${ }^{2} \mathrm{~A}$ Apáthy, ${ }^{3} \mathrm{M}$ Stancikova, ${ }^{3} \mathrm{R}$ Istok. ${ }^{1}$ Department of Pathology, Policlinic of the Hospitaller Brothers of St. John of God in Budapest, Budapest, Hungary; ${ }^{2}$ Department of Rheumatology, National Institute of Rheumatology, Budapest, Hungary; ${ }^{3}$ Department of Biochemistry, Research Institute of Rheumatic Diseases, Piestany, Slovak Republic

\subsection{6/annrheumdis-2001.256}

Background Progressive systemic sclerosis (SSc) is an autoimmune disorder anatomically characterised mainly by successive fibromuscular intimal proliferation of the blood vessels and by the increase of collagen fibres in various organs. The disease is, in general, characterised by the extent of the process and by the stage of the changes.

Objectives The aim of this study was to determine the main complications of SSc in various organs and histologically characterise the interstitial fibrotic process of SSc patients who died in different stages of their disease.

Methods A randomised autopsy population of 11 in-patients (female 10, average age: 53.6 years; male 1 , age of 65 years at death), with clinically confirmed SSc was investigated retrospectively. 30-100 tissue samples from each patient were serially cut and stained with $\mathrm{H}-\mathrm{E}$, or picrosirius red F3BA. ${ }^{1,2}$

Results In 10 of 11 cases, SSc was complicated by a wide spectrum of histological changes of the blood vessels. The lungs showed complex abnormalities such as vascular changes, interstitial pneumonitis, fibrosis or honeycomb-lungs in 6 of 11 patients. In the heart the complex vascular changes were accompanied by multifocal myocardiocytolysis and/or endo-myocardial fibrosis, which led to circulatory failure in 5 of 11 cases. Complex nephropathy in 10 of 11 patients was characterised by interstitial nephritis and/or fibrosis, by mesangioproliferative or membranous glomerulonephritis, and by multifocal cortical (tubular) necrosis. These renal changes led to uremia in 6 of 11 cases. Multifocal acute pancreatitis (of vascular origin) was 